Electronic Physician (ISSN: 2008-5842)

http://www.ephysician.ir

January 2017, Volume: 9, Issue: 1, Pages: 3623-3629, DOI: http://dx.doi.org/10.19082/3623

\title{
Developing a national formulary based on a unified payment system in Iran
}

\author{
Maryam Ahmadi ${ }^{1}$, Morteza Amraei ${ }^{2}$, Mahnaz Samadbeik ${ }^{3}$
}

${ }^{1}$ Ph.D. of Health Information Management, Professor, Department of Health Information Management, School of Health Management and Information Sciences, Iran University of Medical Sciences, Tehran, Iran

${ }^{2} \mathrm{Ph}$.D. Candidate of Health Information Management, Department of Health Information Management, School of Health Management and Information Sciences, Iran University of Medical Sciences, Tehran, Iran

${ }^{3}$ Ph.D. of Health Information Management, Assistant Professor, Department of Health Information Technology, Faculty of Allied Medical Sciences, Lorestan University of Medical Sciences, Khorramabad, Iran

Type of article: Original

\begin{abstract}
Introduction: The national formulary plays an important role in increasing access to medicine and correct drug information based on national considerations. However, this study aimed to provide a model for development of national formulary based on a unified payment system in Iran.

Methods: This study used a combination of descriptive, comparative, and qualitative methods. It was an applied developmental study in 2016. The data were collected using a form based on the World Health Organization's (WHO) standard model for national formulary. Using census method, all national formulary of countries available on the WHO website $(\mathrm{n}=14)$ were selected for study. The similarities and differences of national formulary of these countries and Iran were compared with the WHO's standard model. Then, Iran's national formulary content was determined using comparative study results and opinions of an expert panel consisting of 12 faculty members and assistants of the medicine economy.

Results: Results showed that the content of national formulary in studied countries is consistent with the WHO model. They consisted of four parts: introductory information, medicine information and monograph, appendices, and alphabetical index. In the introductory, which was out of elements of the WHO, the drug selection and advice to patients' criteria in the preliminary information part of used dose and its side effects in drug monograph and information had the highest frequency. The lowest frequency was for medicine pharmacology and pharmacokinetics in the medicine monograph section. The most common data element in the appendix was related to drug interactions, and the lowest frequency was related to hepatic impairment and renal impairment. All data elements were confirmed by an expert panel. They stated that, after the component of common brand name, the drug cost effectiveness and drug code are necessary for each drug in the drug monograph section.

Conclusion: This study provided an updated model and structure for developing national formulary of Iran based on a unified reimbursement system, WHO model, comparative study of national formulary of selected countries, and the opinion of an expert panel in the field of medicine economy. This model may provide reliable information for health employees and managers and improve the effective and safe use of medicines. Also, the creation of drug formulary based on this model and using it may facilitate the selection of standard and highquality medicines from among different companies and brands, comparing them with each other, prescribing high-quality medicine with lower price, and avoiding the impact from advertisements.
\end{abstract}

Keywords: Iran, National Formulary, Model, Structure, World Health Organization

\section{Introduction}

Drugs have a vital role in prevention and treatment of diseases and, if used properly, they can be a simple and useful way to solve health problems. Today, most people do not have access to safe and effective drugs or have little

\section{Corresponding author:}

Morteza Amraei, Department of Health Information Management, School of Health Management and Information Sciences, Iran University of Medical Sciences, Tehran, Iran.

Tel: +98.6632623243, Email: morteza.amraei@yahoo.com

Received: March 23, 2016, Accepted: June 05, 2016, Published: January 2017

iThenticate screening: June 05, 2016, English editing: August 27, 2016, Quality control: October 05, 2016

(C) 2017 The Authors. This is an open access article under the terms of the Creative Commons Attribution-NonCommercialNoDerivs License, which permits use and distribution in any medium, provided the original work is properly cited, the use is non-commercial and no modifications or adaptations are made. 
access. Also, they may be at risk due to using unreliable, low-quality, wrong, and illegal drugs (1). In fact, drugs are always considered as a key factor in the treatment of many diseases. Nowadays, more than 8000 medicinal products are used around the world. According to geographical position, diseases, and financial resources, countries have included some of these drugs in their medicine formulary, and physicians are obliged to prescribe the listed drugs (2). In most cases, taking care of patients in hospitals and other medical centers is associated with prescription and effective use of medication. Considering the abundance and diversity of existing drugs, it seems necessary to make a list of official and usable drugs in order to ensure the provision of best therapy (2). The formulary refers to a limited number of essential and medicines, which are approved by expert medical staff. If it is used properly, it may lead to better health care, better management of medicines, and lower costs of health care for most patients with the same disease. It includes the main information and details of medicines such as their applications, effect mechanisms, contraindications cases, warnings, side effects, drug interactions, used dosage, and advisable points. In fact, the formulary is a reflection of medical staffs' new ideas about drugs and drug therapy. It is revised regularly and is considered as an important and efficient tool for ensuring the fair price of drugs (1-3). Today, many countries (including developing countries) are at the risk of irrational prescriptions and use of drugs. The inappropriate and ineffective use of drugs, especially in developing countries, is extremely common. The side effects of inappropriate drug prescriptions may be summarized as follows:

- Decreased quality of drug therapy, which leads to increased morbidity and mortality;

- Waste of financial resources of patient and pharmaceutical budget of country;

- Increased risk of unwanted side effects such as unwanted medicinal effects and medicinal resistance;

- Using proper drugs with incorrect prescription of dosage and usage period;

- Unnecessary use of expensive drugs such as using third-generation Cephalosporin while its first generation is usable.

Because financial resources and budget of a health system are limited, and much of the funds is spent for drug supplies, the rational drug prescription may prevent wasting national wealth. The cost of irrational use of medicines is high; in some cases, it is caused by improper prescriptions. It is considerable in terms of economic and its adverse effects on the individual and community (4). One of the problems of providing national formulary and achieving its benefits and goals is different performance of insurance organizations in acceptance, review, and approval of medical prescriptions. Given the important role of national formulary in increasing access to medicine and proper drug information based on national considerations, the new drugs must be listed in this formulary; also, their cost coverage must be approved by an insurance company. The different performance of insurance companies in meeting medicine commitments may increase costs and reworks and may lead to deviation from objectives of providing national formulary and implementing electronic prescription $(5,6)$. The formulary provides features such as access to correct, updated, and unbiased medical information, removing invalid pharmaceutical products, and support of cost-effective use of pharmaceutical budget. Therefore, it may be a useful tool to solve some of medication problems. In this regard, the national formulary has correct and high-quality information based on the diseases and position of a country and may be used by a physician as a useful tool for decision-making and prescribing the correct medicine. It may provide useful and updated information to solve many problems related to wrong medicine prescription, drug interactions, unwanted medicine side effects, and contraindications (1). Also, the formulary is a practical tool for nurses and other service providers in health care centers. It is useful for reviewing drug information of patients, updating information, and avoiding many problems that are associated with incorrect medicine prescriptions. Therefore, access to national formulary information is among the main elements of electronic prescriptions. It provides advice and correct drug information for prescriptions and leads to timely decision-making in health care centers $(1,2,7,8)$. In a study entitled (Development of national formulary for Canada) (2004), the results showed that national formulary controls the access to drugs, which are selected based on national considerations. Also, it selects and lists the approved drugs based on disease, funds, and other national considerations. Therefore, the pharmacies and care centers may select and buy high-quality medicines. The national formulary also eliminates managerial costs, which are associated with reviewing, updating, and maintaining various formularies and avoiding reworks (8). A case study, which was conducted in America (2010) showed that increased rate of using recommended drugs may lead to economic savings in more than $50 \%$ of health programs (7). In a study on evaluating the impact of formulary on cost control (2011), the results showed that using formulary reduces the costs of reimbursement and eliminates lack of drug funding. This is done through selection of standard and highquality medicines from among different companies and brands, comparing them with each other, prescribing highquality medicine with lower price, and avoiding the impact of advertisements (9). Ahmadi et al. (2014) analyzed the current situation of electronic prescriptions in Iran. The results showed that there is no instant and on-line access to information resources, which are required for prescriptions. Also, the interaction of electronic prescription with external information systems and various databases such as a formulary system is not possible (3). Countries such as 
Britain, India, Philippines, and Egypt have a national formulary. Canada, like Iran, has different formularies in each state and tries to provide national formulary under supervision of the federal government. Iran also provides formulary for areas such as traditional medicine, medicinal plants, and hospitals to take advantage of its benefits and provide better services. However, there is no unified national formulary based on insurance coverage of unified payment system, which also considers the Fifth Development Plan of Islamic Republic of Iran (aggregation of insurance funds and creation of single payment system) $(8,10-15)$. This study aims to provide a national formulary model based on a unified payment system to create national formulary. Using this formulary, the country's pharmaceutical economy will be improved in the long term, and an important step will be taken in improving health care management and community health. However, we hope that, by preparing and implementing national formulary based on developed model in this study, an appropriate infrastructure will be created for the right decision-making in the medicine field, and access to the latest version of the electronic prescription system will be possible.

\section{Material and Methods}

This study used a combination of descriptive, comparative, and qualitative methods. It was an applied developmental study in 2016. In the first stage, Iranian official formulary was compared with the World Health Organization's standard model for national formulary. In the second stage, using a census method, all national formularies of countries that were available on the website of the World Health Organization $(n=14)$ were selected for study. The similarities and differences of national formulary of these countries were compared. The data were collected using a form based on the World Health Organization's standard model for national formulary. Based on the World Health Organization's model, this form consisted of three parts: introductory information (five main and six extra items), medicine monograph (14 main and 10 extra items), and appendices (five items). At the end of each of these parts, there was a place to record other data elements that did not exist in the model and was specific for studied countries. There were three columns in front of each data element to determine their situation in Iran's current formulary, their frequency in selected countries, and their confirmation by an expert panel (expert opinions about the existence of these elements). The World Health Organization's standard model for national formulary consists of four parts: preliminary information (including introduction, preface, table of contents, glossary, and used abbreviations in formulary text), drug information and monograph (including usage items, dosage, drug interaction, reference to literature, references to appendices), appendix (including drug use during pregnancy and liver and kidney disorders), and full alphabetical index of drugs in formulary. In addition to the main information, there is a series of additional information (including brand name of drug, price, tag information, etc.) on the selected drug, if needed. In the third stage, the proposed data elements for national formulary of Iran, which were extracted from previous stages, were reviewed by an expert panel using the qualitative method. The sample consisted of 12 experts (professors and assistants) in the drug economy field. The experts were selected based on a purposive sampling method. For group discussion, the participants attended a meeting in Shahid Beheshti University of Medical Sciences, pharmacy faculty. The collected data from a comparative study were tabulated and distributed among individuals. Then, discussion was conducted on presented material, and experts agreed on national formulary data elements. The results were given back to them for final approval. Finally, the national model was presented for formulary of Iran.

\section{Results}

Based on the findings, it was indicated that Iranian official formulary is consistent with the World Health Organization standard model. The data were collected in four categories: The introductory part includes introduction, preface, and table of contents; medicine information and monograph include usage level, drug interactions, dosage, side effects, and contraindication; the appendix includes drug use during pregnancy and full alphabetical index (Table 1). The comparative study of selected countries' formularies showed that the formulary of these countries is consistent with World Health Organization's standard model. In the preliminary part of the formulary, the data element of the introduction and preface had the highest frequency (100\%) among selected countries. The lowest frequency (35\%) was for data elements of the method of using glossary and formulary. Also, the data elements of drug selection criteria and advice to patients had the highest frequency $(50 \%)$. In medicine information and the monograph part, the highest frequency (100\%) was for data elements of adverse effects and dosage form and strength. The lowest frequency $(23 \%)$ was for medicine pharmacology and pharmacokinetics. In the appendix part, the most frequency $(50 \%)$ was for drug interactions, and the lowest frequency $(20 \%)$ was for data elements of hepatic impairment and renal impairment. The adverse drug reaction reporting had the highest frequency (35\%) among data elements of studied countries. In the end, the alphabetical index of formulary was provided in selected countries' formulary (Table 2). 
http://www.ephysician.ir

Table 1. Data of reviewing official formulary of Iran based on the World Health Organization model

\begin{tabular}{|l|l|l|}
\hline \multicolumn{2}{|c|}{ Data element and current situation of Iran formulary } \\
\hline Section 1: Preliminary information & $\begin{array}{l}\text { Acknowledgements, }{ }^{*} \text { Introduction or preface, }{ }^{*} \text { Table of contents, } \\
\text { Abbreviations, Units of measurement }\end{array}$ \\
\hline $\begin{array}{l}\text { Section 2: Drug } \\
\text { inf therapeutic }\end{array}$ & $\begin{array}{l}\text { Basic } \\
\text { information }\end{array}$ & $\begin{array}{l}\text { Section heading, }{ }^{*} \text { Introductory text with therapeutic information, Cross } \\
\text { reference to therapeutic information }\end{array}$ \\
\cline { 2 - 3 } & Monograph & $\begin{array}{l}\text { Generic name, }{ }^{*} \text { Dosage form and strength, }{ }^{*} \text { Main indication, } \\
\text { Pharmacology/pharmacokinetics, }{ }^{*} \text { Contraindications, Precautions, } \\
\text { schedule, }{ }^{*} \text { Adverse effects, }{ }^{*} \text { Drug and food interactions, instructions, } \\
\text { warnings }\end{array}$ \\
\cline { 2 - 3 } & Supplementary & $\begin{array}{l}\text { Common brand name(s), }{ }^{*} \text { Price or use of cod or symbol for indicting price, } \\
\text { Prescription category, Patient information, Storage instructions and stability, } \\
\text { Essential drug list number, Main supplier catalogue number, Reimbursement } \\
\text { scheme code, Cross reference to appendix and introductory text }\end{array}$ \\
\hline Section 3: Appendices & $\begin{array}{l}\text { Interactions, Pregnancy, }{ }^{*} \text { Breast feeding, Renal impairment, Hepatic } \\
\text { impairment }\end{array}$ \\
\hline Alphabetical index & \multicolumn{2}{|l}{} \\
\hline
\end{tabular}

*Available

Table 2. Data of reviewing selected countries based on the World Health Organization model

\begin{tabular}{|c|c|c|}
\hline \multicolumn{3}{|c|}{ Data element and frequency of components in the formulary of selected countries } \\
\hline \multirow{3}{*}{$\begin{array}{l}\text { Section 1: } \\
\text { Preliminary } \\
\text { information }\end{array}$} & Basic information & $\begin{array}{l}\text { Acknowledgements (12), Introduction or preface (14), Table of } \\
\text { content (13), Abbreviations (10), Units of measurement (6) }\end{array}$ \\
\hline & $\begin{array}{l}\text { Additional information } \\
\text { at the front of the } \\
\text { national formulary }\end{array}$ & $\begin{array}{l}\text { Instructions on how to use the formulary (4), Glossary (4), Policies } \\
\text { and procedure of the national formulary and national formulary } \\
\text { Committee ( } 7) \text {, National policies and regulations (5), List of changes } \\
\text { (6), General advice to prescribers (8) }\end{array}$ \\
\hline & $\begin{array}{l}\text { Other case pertaining } \\
\text { to this section in } \\
\text { national formulary in } \\
\text { different countries }\end{array}$ & $\begin{array}{l}\text { Drugs to be avoided or used with caution in Liver Disease (1), } \\
\text { Abbreviations of Names of Manufacturers and Local Distributors (1), } \\
\text { Drugs Added to the Formulary (3), Criteria for drug selection ( } 7) \text {, } \\
\text { How the NF is developed (1), Sources of NF information (1), Advice } \\
\text { to patients (7) }\end{array}$ \\
\hline \multirow{4}{*}{$\begin{array}{l}\text { Section 2: Drug } \\
\text { and therapeutic } \\
\text { information }\end{array}$} & Basic information & $\begin{array}{l}\text { Section heading (12), Introductory text with therapeutic information } \\
\text { (6), Cross reference to therapeutic information }\end{array}$ \\
\hline & Monograph & $\begin{array}{l}\text { Generic name (12), Dosage form and strength (14), Main indication } \\
\text { (11), Pharmacology/pharmacokinetics (3), Contraindications (10), } \\
\text { Precautions (10), Dosage schedule (10), Adverse effects (14), Drug } \\
\text { and food interactions (9), Instructions, warnings (5) }\end{array}$ \\
\hline & Supplementary & $\begin{array}{l}\text { Common brand name (s) (7), Price or use of cod or symbol for } \\
\text { indicating price (3), Prescription category (2), Patient information (1), } \\
\text { Storage instructions and stability (4), Essential drug list number (1), } \\
\text { Main supplier catalogue number, Reimbursement scheme code, Cross } \\
\text { reference to appendix and introductory text }\end{array}$ \\
\hline & $\begin{array}{l}\text { Other case pertaining } \\
\text { to this section in } \\
\text { national formulary in } \\
\text { different countries }\end{array}$ & $\begin{array}{l}\text { Use during Pregnancy (1), Advice to the Patient (1), Availability (1), } \\
\text { Counselling (1), Specific considerations (1) }\end{array}$ \\
\hline \multirow[t]{2}{*}{$\begin{array}{l}\text { Section 3: } \\
\text { Appendices }\end{array}$} & Basic information & $\begin{array}{l}\text { Interactions (7), Pregnancy (3), Breast feeding (3), Renal impairment } \\
\text { (2), Hepatic impairment (2) }\end{array}$ \\
\hline & $\begin{array}{l}\text { Other case pertaining } \\
\text { to this section in } \\
\text { national formulary in } \\
\text { different countries }\end{array}$ & $\begin{array}{l}\text { Medicines Adverse Events (1), Medicines Storage Condition (1), } \\
\text { Antimicrobial Resistance (1), Pharmaceutical Products (1), } \\
\text { Therapeutic Drug Monitoring (1), Adverse Drug Reaction Reporting } \\
\text { (4) }\end{array}$ \\
\hline
\end{tabular}


The findings showed that expert panels accepted this four-part structure for national formulary: preliminary information, medicine information and monograph, appendix, and alphabetical index (Table 3). The preliminary part of the accepted formulary included five main data elements and six extra data. However, seven data elements were added based on a comparative study of selected countries. The expert panel detected two data elements (how the NF is developed) and (sources of NF information) of these seven elements as unnecessary and repeated for national formulary and eliminated them (Table 3). The drug and therapeutic information section included 13 main data elements and nine extra data elements.

Table 3. Data of reviewing expert opinion and experts confirmed

\begin{tabular}{|c|c|c|}
\hline \multicolumn{3}{|l|}{ Data element } \\
\hline \multirow{3}{*}{$\begin{array}{l}\text { Section 1: } \\
\text { Preliminary } \\
\text { information }\end{array}$} & Basic information & $\begin{array}{l}\text { Acknowledgements, }{ }^{*} \text { Introduction or preface, }{ }^{*} \text { Table of content, } \\
\text { Abbreviations, }{ }^{*} \text { Units of measurement* }\end{array}$ \\
\hline & $\begin{array}{l}\text { Additional information } \\
\text { at the front of the } \\
\text { national formulary }\end{array}$ & $\begin{array}{l}\text { Instructions on how to use the formulary, }{ }^{*} \text { Glossary, }{ }^{*} \text { Policies and } \\
\text { procedure of the national formulary and national formulary } \\
\text { Committee, }{ }^{*} \text { National policies and regulations, }{ }^{*} \text { List of changes, }{ }^{*} \\
\text { General advice to prescribers* }\end{array}$ \\
\hline & $\begin{array}{l}\text { Other case pertaining } \\
\text { to this section in } \\
\text { national formulary in } \\
\text { Different countries }\end{array}$ & $\begin{array}{l}\text { Drugs to be avoided or used with caution in Liver Disease, }{ }^{*} \\
\text { Abbreviations of Names of Manufacturers and Local Distributors, }{ }^{*} \\
\text { Drugs Added to the Formulary, }{ }^{*} \text { Criteria for drug selection, }{ }^{*} \text { How } \\
\text { the NF is developed, Sources of NF information, Advice to patients* }\end{array}$ \\
\hline \multirow{5}{*}{$\begin{array}{l}\text { Section 2: Drug } \\
\text { and therapeutic } \\
\text { information }\end{array}$} & Basic information & $\begin{array}{l}\text { Section heading,* Introductory text with therapeutic information, } \\
\text { Cross reference to therapeutic information* }\end{array}$ \\
\hline & Monograph & $\begin{array}{l}\text { Generic name, }{ }^{*} \text { Dosage form and strength,* Main indication,* } \\
\text { Pharmacology/pharmacokinetics,* Contraindications,* Precautions, }{ }^{*} \\
\text { Dosage schedule, }{ }^{*} \text { Adverse effects, }{ }^{*} \text { Drug and food interactions, }{ }^{*} \\
\text { Instructions, warnings* }\end{array}$ \\
\hline & Supplementary & $\begin{array}{l}\text { Common brand name(s),* Price or use of cod or symbol for indicting } \\
\text { price,* Prescription category,* Patient information, Storage } \\
\text { instructions and stability,* Essential drug list number, Main supplier } \\
\text { catalogue number, Re-imbursement scheme code, Cross reference to } \\
\text { appendix and introductory text }\end{array}$ \\
\hline & $\begin{array}{l}\text { Other case pertaining } \\
\text { to this section in } \\
\text { national formulary in } \\
\text { different countries }\end{array}$ & $\begin{array}{l}\text { Use during Pregnancy, Advice to the Patient, Availability, } \\
\text { Counselling, Specific considerations }\end{array}$ \\
\hline & $\begin{array}{l}\text { Options required from } \\
\text { expert opinion }\end{array}$ & drug cost effectiveness, drug code \\
\hline \multirow[t]{2}{*}{$\begin{array}{l}\text { Section 3: } \\
\text { Appendices }\end{array}$} & Basic information & $\begin{array}{l}\text { Interactions, }{ }^{*} \text { Pregnancy, }{ }^{*} \text { Breast feeding, }{ }^{*} \text { Renal impairment, } \\
\text { Hepatic impairment* }\end{array}$ \\
\hline & $\begin{array}{l}\text { Other case pertaining } \\
\text { to this section in } \\
\text { national formulary in } \\
\text { different countries }\end{array}$ & $\begin{array}{l}\text { Medicines Adverse Events, Medicines Storage Condition, } \\
\text { Antimicrobial Resistance, Pharmaceutical Products, Therapeutic } \\
\text { Drug Monitoring, Adverse Drug Reaction Reporting }\end{array}$ \\
\hline
\end{tabular}

The expert panel confirmed 12 main elements of 13 main elements. They believed that the data element of (introductory text with therapeutic information) was a redundancy, and the next data element (cross-reference to therapeutic information) was sufficient. However, five data elements were added to this part based on comparative study of selected countries. The expert panel just accepted the data element of (availability) from these five data elements. They considered other elements as unnecessary and overlapped with other data elements in formulary structure (Table 3). The expert panel stated that, after the component of common brand name(s), the drug cost effectiveness and drug code are necessary for each drug in this section (Table 3). The appendix includes five main data elements based on World Health Organization's standard model. The expert panel confirmed all of these data elements as necessary elements for Iran's national formulary. Also, six data elements were added by comparative 
study of selected countries. These elements were not confirmed by an expert panel. In the end, the medicine alphabetical index was provided (Table 3).

\section{Discussion}

According to findings, the World Health Organization model includes four parts: introductory information, medicine information and monographs, appendix, and alphabetical index (15). The findings of this study were consistent with findings of reviewing the structure of national formularies in selected countries and Iranian official formulary (10). The expert panel confirmed this structure for the national formulary of Iran. The confirmation of data elements, including (dosage form and strength) and (adverse effects), in the second part of formulary and the element of (drug interaction) in the appendix repetition of these data elements in national formulary of selected countries, national formulary of Iran, and World Health Organization standard model are consistent with objectives of national formulary (1), including the right prescription of medicine, preventing side effects, and becoming aware of drug interactions. Also, the results of reviewing Iranian official formulary showed that formulary data are not updated, and visitors are recommended to refer to drug lists in the Food and Drug Department website for more information (10). The findings of this study are consistent with the findings of analyzing the current situation of electronic prescription systems in Iran (3) and fast and updated access to needed information resources such as formulary is not possible during prescription service. Given the important role of national formulary in increasing access to medicine and proper drug information based on national considerations, the new drugs must be listed in this formulary; also, their cost coverage must be approved by an insurance company. The different performance of insurance companies in meeting medicine commitments may increase costs and reworks and may lead to deviation from objectives of providing national formulary and implementing electronic prescriptions $(5,6)$. In the introductory section, the expert panel confirmed the data elements of (list of changes), (drugs added to formulary and drug), and (criteria for drug selection); and in drug and therapeutic information part, they confirmed the (availability) data element. They argued that these data elements inform visitors of recent drug changes, the drugs added to national formulary, the availability of medicines in health centers, and drug selection criteria based on national considerations. Therefore, visitors will not be referred to other centers for more information in this context. In the drug and therapeutic information, the expert panel stated that, after the component of common brand name(s), the drug cost effectiveness and drug codes are necessary for each drug. The data element of (drug cost effectiveness) is consistent with the objectives and data elements of national formulary of England (12). Using the Ministry of Health and Medical Education coding system reduces the costs of dispersed and repetitive actions, contributes in developing ontologybased health information systems, creates integration among different health information systems, helps with better and easy electronic transmission of data among different systems, and develops electronic health records in country. Also, it may be an appropriate infrastructure for electronic prescriptions and help manage issues related to reimbursement costs (16).

\section{Conclusions}

This study provided an updated model and structure for developing a national formulary of Iran based on a unified reimbursement system, WHO model, comparative study of national formulary of selected countries, and opinion of an expert panel in the field of medicine economy. The importance of these findings is that this model can provide reliable information for health employees and managers and improve the effective and safe use of medicines. Also, the creation of drug formulary based on this model and using it may facilitate the selection of standards and highquality medicines from among different companies and brands, comparing them with each other, prescribing highquality medicine with a lower price, and avoiding the impact from advertisements. As the infrastructure for electronic prescriptions and due to using unified codes for each drug and easier and better electronic transfer of data between different systems, it may be an effective tool for solving problems related to reimbursement in health care centers. It is recommended to prepare a national formulary based on the finding of this study to receive the mentioned benefits and prepare the electronic prescription infrastructure. Also conducting a supplementary study in the preparation of an electronic prescribing minimum data set with the Delphi method could be the appropriate path for future studies on this topic.

\section{Acknowledgments:}

This study was part of the research project supported by Iran University of Medical Science (grant no.: 95-01-13627251). The work described here was carried out independent of the funders. In this section, we thank professors and assistants in the drug economy field at Shahid Beheshti University of Medical Sciences, pharmacy faculty for participate in the meeting of the panel of experts. 


\section{Conflict of Interest:}

There is no conflict of interest to be declared.

\section{Authors' contributions:}

All authors contributed to this project and article equally. All authors read and approved the final manuscript.

\section{References:}

1) Laing R, Tisoki K. How to Develop a National Formulary Based on The WHO Model Formulary: a Practical Guide. World Health Organization. 2004; 45.

2) Sohravardi M. Guide for rational consumption and drug prescription. Esfahan: kankash. 2002.

3) Ahmadi M, Samadbeik M, Sadoughi F. Modeling of Outpatient Prescribing Process in Iran: A Gateway toward Electronic Prescribing System .Iran J Pharm Res. 2014; 13(2): 725-38. PMID: 25237369, PMCID: PMC4157049.

4) Fischer MA, Vogeli C, Stedman M, Ferris T, Brookhart MA, Weissman JS. Effect of electronic prescribing with formulary decision support on medication use and cost. Arch Intern Med. 2008; 168(22): 2433-9. Doi: 10.1001/archinte.168.22.2433. PMID: 19064827.

5) Tahermirzaei M, shahi L. procedure unification of Basic insurance organizations. Sepid. 2015; 11(684).

6) Zareh H, yazdani N, Azadi M. provide a model for private health insurance in Iran. Teb VA tazkieh. 2015; $20(1,2)$

7) Kjos AL, Schommer JC, Yuan Y. A Comparison of Drug Formularies and the Potential for Cost-Savings. Am Health Drug Benefits. 2010; 3(5): 321-30. PMID: 25126325, PMCID: PMC4106615.

8) Aidan H. Law S. A national formulary for Canada. Canadaian public policy. 2004: 30(4): 445-52. Doi: 10.2307/3552524. Available from: http://www.jstor.org/stable/3552524?seq=1\#page_scan_tab_contents

9) Huskamp HA, Epstein AM, Blumenthal D. The impact of a national prescription drug formulary on prices, market share, and spending: lessons for Medicare? Health Aff (Millwood). 2003; 22(3): 149-58. PMID: 12757279 .

10) Ministry of health of the Islamic Republic of Iran, Food and Drug Department. Iranian official formulary. Tehran: Shahid Beheshti University of Medical Sciences and Health Services. 2007.

11) Scientific center. Research and development gol daru plant Formulary Company. Eshahan: Scientific center, research and development gol daru plant Formulary Company, 2007.13. British 13. National Formulary. London: BMJ Group. 2009.

12) Government of India Ministry of Health \& Family Welfare. National Formulary of India. Ghaziabad: Indian Pharmacopeia Commission. 2001.

13) Ministry of Health \& Population. Egyptian National Formulary. Centeral Administration of Pharmaceutical Affairs. 2007.

14) Department of Health. Philippine National Drug Formulary. The National Formulary Committee. 2008.

15) Marc C, Maria K, Suzanne R. WHO model formulary. World Health Organization. 2008.

16) Ministry of health of the Islamic republic of Iran. Assessment indicators hospital information system. 2012. 